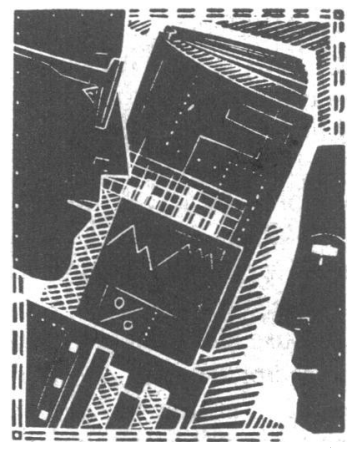

\title{
Community obstetric care in West Berkshire
}

\author{
Patricia Street, Michael J Gannon, Edmund M Holt
}

\section{Abstract}

Objective-To assess the effects of a revised obstetric booking policy whereby all low risk pregnant women received their antenatal care entirely in the community.

Design-Comparison of the distribution of antenatal clinic attendances, transfers, and perinatal mortality rates for 1987 and 1989, before and after introduction of the revised policy.

Setting-West Berkshire Health District.

Subjects - All women who delivered with a registrable birth in the district in 1987 (5817 women) and 1989 (5372).

Main outcome measures-Attendances at community and consultant antenatal clinics; bookings transferred from community care to consultant care; perinatal mortality rates.

Results - Of 5372 women delivering in West Berkshire in $1989,3185(58.3 \%)$ were originally booked for general practitioner-midwife care, of whom 1567 $(49.2 \%$ of general practitioner-midwife bookings) were transferred to consultant care. 1618 women (30.1\% of all women delivered) received their entire obstetric care from general practitioners and midwives. Attendance at hospital antenatal clinics was reduced by $16 \%$. In 1989 the perinatal mortality rates (1987 values) for the district were 6.3 (7.6) per 1000 births overall; 8.2 (8.3) per 1000 consultant bookings; $5.0(4.7)$ per 1000 for community bookings; and 10.2 (14.4) per 1000 for women transferred to consultant care.

Conclusion-Antenatal care of low risk pregnant women may safely be provided by their general practitioner and midwife.

\section{Introduction}

In 1988 the consultant obstetric unit at this hospital faced several problems. Four consultants were supervising more than 5000 maternities per year, antenatal clinics were overcrowded, and women had to wait an unreasonable time to be seen. A time and motion study concluded that a timed appointment system was unworkable. The consultant labour ward had only nine labour rooms. On the same floor there was a general practitioner unit with two labour rooms and eight postnatal beds. Bed occupancy was low in this unit and the other general practitioner units in the district, in Wokingham and Newbury.

In 1987 there were 4954 deliveries in the consultant unit and 863 deliveries in the three general practitioner units (table I). Attempts to alleviate the situation by increasing bookings in the peripheral units resulted in a quadrupling of flying squad calls, with consequent disruption of the smooth running of the consultant unit. The health authority then withheld funding for essential anaesthetic equipment for the flying squad. This led to the closure of the isolated general practitioner maternity units and the transfer of the extra deliveries to this hospital, which could not accommodate the extra workload. In June 1988 a booking policy was introduced whereby the general practitioner and midwife assumed full responsibility for low risk pregnancies. All women were delivered in an integrated labour ward, incorporating both consultant and community units.

\section{Subjects and methods}

A revised booking policy was drawn up by one of us (EMH) to identify women suitable for community care. All women booked for community care had to be aged 16-37, between $46 \mathrm{~kg}$ and $90 \mathrm{~kg}$ in weight, at least $152 \mathrm{~cm}$ in height, and have a singleton pregnancy. Women with identified risk factors were excluded - for example, those with a history of caesarean section or rotational forceps delivery; a history of myomectomy or pelvic floor repair; diabetes mellitus, hypertension, or thrombosis. The risks associated with a history of low cavity forceps delivery or postpartum haemorrhage were not considered sufficient to necessitate consultant care as all women were delivered in an integrated labour ward. Women who fulfilled the criteria for community care did not have the choice of opting for consultant care.

The general practitioner submitted a booking form that was assessed by one of us (PS). Ultrasonography was arranged; if a multiple pregnancy or fetal abnormality was diagnosed the woman was then booked for consultant care. In doubtful cases women were asked to attend the hospital antenatal clinic for a consultant opinion.

Women receiving community care were usually seen at each visit either by their general practitioner or by their community midwife. Community midwives conduct their own clinics instead of assisting at general practitioner antenatal clinics. The findings were recorded on to a standardised cooperation card, which incorporated a symphysis-fundal height measurement chart.

The general practitioner and midwife assumed full and legal responsibility for managing the women, and they decided whether or not to transfer care to a consultant. Referral procedures were streamlined; any general practitioner or midwife could refer a woman for a specialist opinion on the same day without prior appointment. All hospital antenatal clinics had spaces

TABLE I-Summary of bookings, transfers, and deliveries in Wes Berkshire, in 1987. Figures are numbers of women, unless otherwise stated

\begin{tabular}{lr}
\hline & No \\
\hline Women delivered & 5817 \\
Babies born & 5883 \\
Booking: & 4537 \\
In consultant unit & 1280 \\
In general practitioner unit & 417 \\
Transfers to consultant unit & 4954 \\
Deliveries: & 863 \\
In consultant unit & \\
In general practitioner unit & \\
\hline
\end{tabular}

Correspondence to:

Miss Street. 
reserved for such referrals where women were seen by a registrar or consultant. Time and facilities were specifically made available to perform any necessary ultrasonography. The policy for consultant antenatal care did not change.

The labour ward in the hospital unit was enlarged by incorporating the general practitioner unit. There are now 13 delivery rooms and two six bed wards that may be used for women in early labour or requiring intensive nursing care. Women booked for community care could receive intrapartum care from their general practitioner or community midwife or, alternatively, the general practitioner could nominate the midwives at the hospital to provide this care. Hospital midwives were given additional responsibility: after suitable training they established intravenous infusions, prescribed oxytocin to augment labour in primigravidas, and sutured episiotomies or tears.

Women in labour in the consultant unit had continuous cardiotocographic monitoring. Those booked for community care had cardiotocographic monitoring if an abnormality of the fetal heart rate was detected by auscultation, meconium was noted, the midwife suspected a problem, or epidural anaesthesia was used. A 24 hour epidural anaesthetic service was available for all women in labour. During labour the transfer of care

TABLE II-Summary of bookings, transfers, and deliveries in consultant and general practitioner-midwife units, 1989. Figures are numbers of women, unless otherwise stated

\begin{tabular}{lc}
\hline & No \\
\hline Women delivered & \multicolumn{2}{c}{5372} \\
Babies born & \multicolumn{2}{c}{5434} \\
Bookings: & \multicolumn{2}{c}{2187} \\
$\quad$ Consultant unit & 3185 \\
General practitioner and midwife unit & 1655 \\
$\quad$ Primigravidas & 1530 \\
$\quad$ Multigravidas & \multicolumn{2}{c}{1567} \\
Transfers to consultant unit & \multicolumn{2}{c}{521} \\
$\quad$ Primigravidas & \multicolumn{2}{c}{546} \\
Multigravidas & \multicolumn{2}{c}{3754} \\
Deliveries: & \multicolumn{2}{c}{1618} \\
$\quad$ Consultant unit & \multicolumn{2}{c}{} \\
\hline
\end{tabular}

TABLE III - Perinatal deaths in seven women booked for community care when care was transferred before onset of labour or diagnosis of intrauterine death

\begin{tabular}{|c|c|c|c|c|}
\hline $\begin{array}{l}\text { Transfer } \\
\text { (weeks) }\end{array}$ & $\begin{array}{l}\text { Delivery } \\
\text { (weeks) }\end{array}$ & $\begin{array}{l}\text { Weight } \\
\text { of baby } \\
\text { (g) }\end{array}$ & Mode of delivery & Comment \\
\hline \multicolumn{5}{|c|}{ Antepartum intrauterine death } \\
\hline 26 & 36 & 2085 & Spontaneous vaginal & True knot in cord \\
\hline 31 & 34 & 1000 & Spontaneous vaginal & Trisomy 18 \\
\hline 20 & 40 & 2935 & Neville-Barnes forceps & Hypoplastic left ventricle \\
\hline \multicolumn{5}{|c|}{ Intrapartum intrauterine death } \\
\hline 32 & 41 & 2965 & Spontaneous vaginal & Hypoxia due to cord tight around neck \\
\hline & & & Neonatal death & \\
\hline 26 & 31 & 1170 & Caesarean section & Trisomy 13 \\
\hline 28 & 28 & 1090 & Caesarean section & Massive abruption \\
\hline 26 & 27 & 1110 & Spontaneous vaginal & Preterm rupture of membranes \\
\hline
\end{tabular}

TABLE IV-Perinatal deaths in nine women booked for community care when care was not transferred before onset of labour or diagnosis of intrauterine death

\begin{tabular}{|c|c|c|c|c|}
\hline $\begin{array}{l}\text { Transfer } \\
\text { (weeks) }\end{array}$ & $\begin{array}{l}\text { Delivery } \\
\text { (weeks) }\end{array}$ & $\begin{array}{l}\text { Weight } \\
\text { of baby } \\
\text { (g) }\end{array}$ & Mode of delivery & Comment \\
\hline \multicolumn{5}{|c|}{ Antepartum intrauterine death } \\
\hline 38 & 38 & 2550 & Spontaneous vaginal & $\begin{array}{l}\text { Neuroscopic diagnosis of intrauterine growth } \\
\text { retardation }\end{array}$ \\
\hline 33 & 33. & 1680 & Spontaneous vaginal & Hypoxia \\
\hline 35 & 35 & 1760 & Spontaneous vaginal & $\begin{array}{l}\text { Pre-eclamptic toxaemia, hypoxia, placental } \\
\text { insufficiency }\end{array}$ \\
\hline 36 & 36 & 2050 & Spontaneous vaginal & Maternal anaemia, hypoxia \\
\hline 39 & 39 & 3420 & Spontaneous vaginal & Hypoxia due to true knot in cord \\
\hline 33 & 33 & 2410 & Spontaneous vaginal & Unexplained \\
\hline 30 & 30 & 735 & Spontaneous vaginal & Hypoxia due to placental insufficiency \\
\hline \multicolumn{5}{|c|}{ Neonatal death } \\
\hline 24 & 24 & 750 & Spontaneous vaginal & Preterm labour \\
\hline 40 & 40 & 4110 & Neville-Barnes forceps & Listeriosis \\
\hline
\end{tabular}

TABLE V-Perinatal mortality rate per 1000 births, 1989

\begin{tabular}{lrr}
\hline & Rate & $\begin{array}{r}\text { No of } \\
\text { births }\end{array}$ \\
\hline Women booked in consultant unit & $8 \cdot 2$ & 2187 \\
Women booked in general practitioner and midwife unit & $5 \cdot 0$ & 3185 \\
Women transferred to consultant care & $10 \cdot 2$ & 1567 \\
Overall rate for unit & $6 \cdot 3$ & 5434
\end{tabular}

TABLE VI-Perinatal mortality rate per 1000 births, 1987

\begin{tabular}{lrr}
\hline & Rate & $\begin{array}{r}\text { No of } \\
\text { births }\end{array}$ \\
\hline Women booked in consultant unit & $8 \cdot 3$ & 4537 \\
Women booked in general practitioner unit & $4 \cdot 7$ & 1280 \\
Women transferred to consultant care & $14 \cdot 4$ & 417 \\
Overall rate & $7 \cdot 6$ & 5883
\end{tabular}

to the consultant is achieved simply and quickly by referral to the registrar on call. A policy of discharge within 48 hours after a normal delivery was also introduced.

\section{Results}

In West Berkshire from 1 January to 31 December 1989 there were 5434 births to 5372 women (table II). Originally, $3185(59 \cdot 2 \%)$ of these women were booked for community care, but $1567(49 \cdot 2 \%$ of general practitioner-midwife bookings) were transferred to consultant care. The remaining 1618 women $(50.8 \%$ of general practitioner-midwife bookings and $30 \cdot 1 \%$ of all women delivered in West Berkshire) had their entire care provided by their general practitioner and midwife. In all, $189(6 \%)$ of proposed community bookings were unsuitable when the booking forms were screened by one of us.

After the scheme was introduced the mean number of attendances per month at the consultant antenatal clinics fell from 1424 (range 1294-1545) to 1193 (1007-1401). The mean monthly attendances at the general practitioner-midwife clinics rose from 1395 (1165-1567) to 2625 (2259-2901).

The care of 975 women $(30.6 \%$ of general practitionermidwife bookings) was transferred antenatally. The main reasons were postmaturity (284 women), pregnancy induced proteinuric hypertension (100), suspected intrauterine growth retardation (155), malpresentation (83), antepartum haemorrhage (84), decreased fetal movements (53), and non-proteinuric hypertension (36). A further 516 women $(16 \cdot 2 \%)$ were transferred during labour. The main reasons were prolonged second stage (195), fetal distress determined by cardiotocography (89), preterm labour of less than 36 weeks' gestation (47), breech presentation (17), other abnormal presentation (17), and meconium stained liquor (28). Seventy six women $(2 \cdot 4 \%)$ were transferred after delivery, mainly owing to postpartum haemorrhage (45) and raised blood pressure (15).

In the consultant unit there were 18 perinatal deaths (13 stillbirths and five early neonatal deaths), compared with 16 perinatal deaths in women booked for community care (11 stillbirths and five early neonatal deaths). Of these 16 women, seven were transferred to the consultant unit antenatally (table III), the reasons for transfer being intrauterine growth retardation (three women), preterm rupture of membranes (two), abnormal findings on ultrasonography (one), and massive antepartum haemorrhage (one). Nine women were still under the care of the general practitionermidwife unit at the onset of labour or diagnosis of intrauterine death (table IV).

The perinatal mortality rate for the whole unit in 1989 was 6.3 per 1000 births (table V) and that for women booked for community care was $5 \cdot 0$ per 1000 
births. The corresponding rates for 1987 were $7 \cdot 6$ and $4 \cdot 7$ per 1000 births (table VI)

The midwives responded positively to their increased responsibility. In March 1988, before the community care scheme was introduced, $22 \%$ of midwifery posts in this hospital were unfilled. Understaffing was reduced to 3\% in March 1990.

\section{Discussion}

The system described is designed to utilise more fully the skills of general practitioners and midwives. The increased requirement for community antenatal care would have overburdened many general practitioners, so community midwife antenatal clinics were introduced into nearly all practices. The average monthly attendance at these clinics doubled between 1987 and 1989. The monthly attendances at combined general practitioner-midwife clinics fell from 2449 in 1987 to 658 in 1989.

The increased responsibility taken by the community midwives seems to have improved community obstetric practice. Increased communication between community staff and their hospital counterparts and regular short labour ward attachments are an excellent catalyst to uniformity of practice within the area.

The screening of all our general practitioner-midwife booking forms by an experienced specialist detected $6 \%$ of women who were unsuitable for community obstetric care; these women were booked for the consultant unit. We found that a routine booking visit by all women was unnecessary. Additional consultant staffing to expand antenatal clinics, as suggested by others, ${ }^{23}$ may not be an effective or necessary solution.

Antenatal transfers $(30 \cdot 6 \%$ of general practitionermidwife bookings) were accommodated in the redesigned clinics. During the first months of the new scheme it became apparent that many referrals for a consultant opinion could be transferred back to community care after one or two visits to the hospital antenatal clinic. A reduction in the transfer rate was apparent as the consultants became used to returning women to community care.

Transferring women back to community care after referral remains a problem. Of 155 women tranferred owing to suspected intrauterine growth retardation, only 36 had infants with birth weights below the 10th centile; the remaining 119, in whom intrauterine growth retardation was not present, were not returned to community care. Fourteen women who remained in the general practitioner-midwife unit delivered infants with birth weights below the 10th centile.

Few general practitioners today have the time, energy, or desire to reclaim the lost territory of intrapartum care, ${ }^{+}$and most in this area nominate the hospital midwives to provide intrapartum care. Other commitments and distance from the delivery unit makes the provision of intrapartum care an unrealistic aim for many general practitioners in West Berkshire.

The safety of intrapartum care is of prime concern. A previous prospective study in West Berkshire showed that low risk women booked with general practitioners, and their infants, experienced no greater morbidity or mortality than those in the consultant units. ${ }^{5}$ Recent reports from other areas have suggested the opposite, for both integrated ${ }^{2}$ and isolated ${ }^{3}$ general practitioner maternity units. Among the problems cited were inappropriate booking, delayed transfers, ${ }^{2}$ and poor intrapartum care. ${ }^{3}$ Care has been taken in West Berkshire to avoid these pitfalls. Of the perinatal deaths among women booked for the general practitioner-midwife unit, $31 \%$ were predicted as at risk, at least three weeks in advance, and care had been transferred. Transferred women form a selected high risk population, and the perinatal mortality rate among them would be expected to be higher $(10.2$ per 1000 births). The rate in women booked for community care calculated according to the same criteria as in a recent survey ${ }^{3}$ would be 1.3 per 1000 births. The only perinatal deaths after intrapartum transfer occurred in a preterm infant of 24 weeks' gestation and an infant with listeriosis. With regard to safety, the perinatal mortality rate in West Berkshire in the first full year of the new policy was 6.3 per 1000 . This is the lowest figure ever recorded.

The roles of the midwife, the general practitioner, and the obstetrician in providing maternity care are not strictly defined. The management of pregnancy in the United Kingdom has evolved from home confinement supervised by a midwife, through general practitioner domination, to the present system of hospital based consultant care. The reduction in maternal mortality, which is attributed by many as being due to the advance of the specialty of obstetrics, has ensured the place of the specialist obstetrician. ${ }^{4}$

Most births now occur in units with more than 2000 deliveries a year. ${ }^{6}$ The result is overcrowded hospital antenatal clinics, where many women are seen by relatively inexperienced junior medical staff. It seems logical to distinguish between normal low risk pregnancies and abnormal high risk pregnancies. If the responsibility for normal pregnancies can be safely returned to the patient's general practitioner and community midwife the hospital based specialist should have more time to devote to those women with significant risk factors, who really need such skill.

Attempts to devolve maternity care have relied mainly on the shared care system, ${ }^{7}$ whereby every woman is assessed at a hospital booking clinic to plan her pregnancy. This has two drawbacks: it is time consuming for the consultant and it commonly fails to identify women who later develop complications. ${ }^{8}$ Much of the subsequent antenatal care is provided by the general practitioner, who may feel frustrated by his or her lack of clinical independence. ${ }^{4}$ Two thirds of community midwives do not normally provide any antenatal care independently of the general practitioner. ${ }^{9}$ There is widespread feeling among midwives that they are not being allowed to carry out the job for which they have been trained. ${ }^{10}$

Many women prefer midwives and general practitioners to consultants and high tech medicine for their antenatal care, ${ }^{11}$ yet 10 times more women favour delivery in hospital to home birth. "Most would opt for consultant care if there was a risk of something going wrong. ${ }^{12}$ The community obstetric care provided by the general practitioner-midwife unit seems to be a satisfactory solution for most women and has successfully replaced the traditional shared care in West Berkshire.

We thank A Wheble and S Kennedy for their help in preparing this manuscript, and Sally Loveday for her help in obtaining the maternity records.

1 Brudenell JM. Future of general practitioner obstetrics: discussion paper. $f R$ Soc Med 1983;76:197-9.

2 Bryce FC, Clayton JK, Rand RJ, Beck I, Farquharson DIM, Jones SF. General practitioner obstetrics in Bradford. BMJ 1990;300:725-7.

3 Sangala V, Dunster G, Bohin S, Osborne JP. Perinatal mortality rates in isolated general practitioner maternity units. $B M \mathcal{F}$ 1990;301:418-20.

4 Loudon I. Obstetrics and the general practitioner. BMF 1990;301:703-7.

5 Taylor GW, Edgar W, Taylor BA, Neal DG. How safe is general practitioner obstetrics? Lancet 1980;ii:1287-9.

6 Chamberlain G. Obstetrics after the white paper. BMF 1989;298:1702-3.

7 Bull M. GP obstetrics: making the most of shared care. Practitioner 1989;233: 211-5.

8 Reynolds JL, Yudkin PL, Bull MJV. General practitioner obstetrics: Does risk prediction work? I R Coll Gen Pract 1988;38:307-10.

9 Marsh GN, Cashman HA, Russell IT. General practitioner obstetrics in the Northern region in 1983. BMF 1985;290:901-3.

Northern region in 1983. BMF 1985;290:901-3.
10 Drife JO. My grandchild's birth. BMJ 1988;297:1208.

11 National Council of Women of Great Britain. Women's health charter. London: National Council of Women of Great Britain, 1990 .

12 Taylor A. Maternity services: the consumer's view. $7 \mathrm{R}$ Coll Gen Pract 1986;36:157-60.

(Accepted 21 fanuary 1991) 